
javanica. Horticultura Brasileira, Brasília, v. 19, n. 2, p. 115-117, julho 2.001.

\title{
Avaliação da resistência de genótipos de quiabeiro à infestação por Meloidogyne incognita raça 2 e M. javanica.
}

\author{
Gilmar Efrem Martinello $^{1 /}$; Nilton R. Leal ${ }^{1 /}$; João Carlos Pimentel ${ }^{2 /}$ \\ ${ }^{1}$ UENF, CCTA, LMGV, Av. Alberto Lamego, 2000 - Horto, 28.015-620 Campos dos Goytacazes-RJ, ${ }^{2 /}$ UFRRJ, IB, Antiga Rodovia Rio - \\ São Paulo, Km 47, 23.851-970 Seropédica RJ. E.mail: gilmartinello@hotmail.com
}

\begin{abstract}
RESUMO
Vinte e dois genótipos de quiabeiro (Abelmoschus spp.) foram avaliados para resistência à Meloidogyne incognita raça 2 e $M$. javanica. Estes materiais, mantidos no Banco de Germoplasma da Universidade Estadual do Norte Fluminense, constam de quatro espécies selvagens Abelmoschus manihot (CGO 8655), A. caillei (CGO 8656), A. tetraphyllus (CGO 8657) e A. ficulneus (CGO 8658); 16 linhas de A. esculentus na sétima geração de autofecundação, resultantes de inter-cruzamentos do genótipo PI-357991 (supostamente resistentes a nematóides) com as cultivares Piranema e Santa Cruz 47. Essas cultivares serviram como padrão de suscetibilidade. As plantas foram inoculadas separadamente com 5.000 ovos/segundo estádio juvenil (J2) de $M$. incognita raça 2 e $M$. javanica. Não houve diferença significativa com relação à resistência dos materiais a $M$. javanica. Os genótipos descendentes de 'PI-357991' mostraram-se segregantes para a reação de resistência, sendo que entre estes 'CGO $8180 \mathrm{~A}_{7}$ ' apresentou o maior nível de tolerância à raça 2 de $M$. incognita. As espécies silvestres também não mostraram alguma fonte de resistência. As altas temperaturas ocorridas no período do experimento, podem ter aumentado a suscetibilidade dos genótipos aos dois patógenos.
\end{abstract}

Palavras-chave: Abelmoschus spp., avaliacão de germoplasma, nematóides-das-galhas.

\begin{abstract}
Resistance of okra genotypes to Meloidogyne incognita race 2 and $M$. javanica.

Twenty two okra genotypes were evaluated for resistance to $M$. incognita race 2 and $M$. javanica. The Universidade Estadual do Norte Fluminense (Brazil) maintains okra genotypes in the germplasm collection, consisting of four wild Abelmoschus species and $16 \mathrm{~F}_{7}$ lines obtained from crosses between PI-357991 (considered resistant to root-knot nematodes) and the local cvs, Piranema and Santa Cruz 47 (both susceptible to nematodes). No resistance was observed among okra genotypes to infection by $M$. javanica. The 16 $\mathrm{F}_{7}$ lines segregated for pathogenic reaction, and the CGO 8180A presented the highest resistance level to $M$. incognita race 2 . The wild species did not show genetic resistance to both pathogens. High temperature occurring during experimental period could have increased the genotype susceptibility to the pathogens.
\end{abstract}

Keywords: Abelmoschus spp., germplasm evaluation, root-knot nematode.

(Aceito para publicação em 17 de maio de 2.001)

$\mathrm{O}$ quiabeiro, Abelmoschus esculentus (L.) Moench, é uma Malvaceae de regiões tropicais e sub-tropicais de baixas altitudes da Ásia, África e América (Charrier, 1984). Este vegetal é importante fonte de vitaminas e sais minerais, incluindo cálcio, que são frequentemente carentes na dieta dos países em desenvolvimento (Hamonet al., 1990). No Brasil, o quiabeiro vem sendo cultivado principalmente no Estado do Rio de Janeiro, destacadamente na região metropolitana e baixada litorânea. As cultivares Piranema e Santa Cruz 47 são as mais utilizadas nestas regiões, alcançando bons níveis de produção, apesar de apresentarem alta suscetibilidade a nematóides.

$\mathrm{O}$ emprego de cultivares resistentes traz a vantagem de requerer pequena ou nenhuma tecnologia e consequentemente ser de baixo custo. Ainda, dispensa a necessidade da rotação de culturas, permitindo melhor uso da terra (Trudgil, 1991). Os nematicidas, por sua vez, são anti-econômicos pois requerem mão-deobra na aplicação, são de alto custo e nem sempre apresentam a eficiência desejada. Outra desvantagem do uso de nematicidas consiste no risco de contaminação do ambiente e do ser humano.

As fontes de resistência a nematóides, identificadas até o momento, são muito pouco estudadas quando comparadas à diversidade genética existente (Trudgill, 1991). Neste sentido, alguns estudos recentes têm revelado uma ampla dispersão de resistência às diferentes raças de Meloidogyne em diversas culturas (Sasser, 1980). Quase todas as fontes/tipos de resistência genética identificadas e usadas no melhoramento são aos endoparasitas Ditylenchus, Meloidogyne, Heterodora ou Globodera spp e são conferidas por um gene maior dominante (Sidhu \& Webster, 1981). Entretanto, as fontes de resistência à Meloidogyne em algodão, $H$. glicines em soja e G. pallida em batata, são poligênicas (Trudgill, 1991). Alguns genes conferem resistência a mais de uma espécie de nematóides. Exemplos incluem o gene $M i$ que confere resistência a $M$. incognita, $M$. javanica e $M$. arenaria. Tal gene proporciona também resistência poligênica em Solanum vernei a $G$ rostochiensis e G. pallida e monogênica em Glycine sp. 
a H. glicines e Pratylenchus reniformes (Cook, 1991).

Este trabalho teve por objetivo avaliar genótipos de quiabeiro quanto à resistência a M.incognita raça 2 e $M$. javanica.

\section{MATERIAL E MÉTODOS}

Populações monoespecíficas de $M$. incognita raça 2 e $M$. javanica, doadas pelo IAPAR e UFV, respectivamente, foram cultivadas em vasos contendo mistura de solo e esterco de curral, previamente tratado com o brometo de metila onde plantou-se tomateiro cv. Santa Cruz. A extração de ovos para a preparação do inóculo utilizado seguiu a metodologia proposta por Hussey \& Barker (1973), citados por Tihohod (1989).

Foram avaliados 22 genótipos de quiabeiro na Estação Experimental da PESAGRO-Rio, Seropédica, em outubro de 1994, atualmente mantidos no Banco de Germoplasma da UENF. Os genótipos em teste constaram de quatro espécies silvestres [Abelmoschus manihot (CGO 8655), A. caillei (CGO 8656), A. tetraphyllus (CGO 8657), A. ficulneus (CGO 8658)], 16 linhas de A. esculentus na sétima geração de autofecundação [resultantes de inter-cruzamentos de PI357991 (supostamente resistentes a nematóides)] e duas cultivares locais ('Piranema' e 'Santa Cruz 47'), suscetíveis e utilizadas como controle.

Dois experimentos foram conduzidos simultaneamente. No primeiro, cada genótipo recebeu 5.000 ovos/J2 (segundo estádio juvenil) de $M$. incognita raça 2. No segundo, esses mesmos genótipos receberam, por sua vez, a mesma concentração de inóculo, empregando-se $M$. javanica como patógeno. Foram avaliados três indivíduos de cada genótipo para ambos os experimentos. Utilizouse o delineamento inteiramente casualizado com três repetições. As plantas inoculadas foram conduzidas em casa-de-vegetação, com temperatura variando entre 15 e $43^{\circ} \mathrm{C}$.

$\mathrm{Na}$ avaliação dos resultados, as raízes foram removidas e coloridas em solução de Floxine B (15 mg/l de água) por 15 a 20 minutos, para contagem de massas de ovos ou ootecas. Utilizou-se a escala de 1 a 5 para caracterizar os

Tabela 1. Incidência de Meloidogyne incognita raça 2 em 22 genótipos de quiabeiro (média de três repetições), Seropédica, PESAGRO-Rio, 1994.

\begin{tabular}{llc}
\hline & \multicolumn{1}{c}{ Genótipo $^{* *}$} & M. incognita raça $^{2}$ \\
\hline 1 & Cv Santa Cruz 47 (A. esculentus) & $5,0 \mathrm{a}^{*}$ \\
2 & Cv Piranema (A. esculentus) & $5,0 \mathrm{a}$ \\
3 & CGO 8180A10 & $5,0 \mathrm{a}$ \\
4 & CGO 8166A5 & $5,0 \mathrm{a}$ \\
5 & CGO 8185A13 & $5,0 \mathrm{a}$ \\
6 & CGO 8166A2 & $5,0 \mathrm{a}$ \\
7 & CGO 8166A4 & $5,0 \mathrm{a}$ \\
8 & CGO 8186A7 & $5,0 \mathrm{a}$ \\
9 & CGO 8180A5 & $5,0 \mathrm{a}$ \\
10 & CGO 8165A6 & $5,0 \mathrm{a}$ \\
11 & CGO 8161A5 & $4,6 \mathrm{a}$ \\
12 & CGO 8165A10 & $4,6 \mathrm{a}$ \\
13 & CGO 8180A8 & $4,6 \mathrm{a}$ \\
14 & CGO 8180A3 & $4,3 \mathrm{ab}$ \\
15 & CGO 8180A13 & $4,3 \mathrm{ab}$ \\
16 & CGO 8655 (A. manihot) & $4,3 \mathrm{ab}$ \\
17 & CGO 8657 (A. tetraphillus) & $4,0 \mathrm{ab}$ \\
18 & CGO 8656 (A. caillei) & $4,0 \mathrm{ab}$ \\
19 & CGO 8176 A2 & $4,0 \mathrm{ab}$ \\
20 & CGO 8658 (A. ficulneus) & $3,6 \mathrm{ab}$ \\
21 & CGO 8166A7 & $3,3 \mathrm{ab}$ \\
22 & CGO 8180A7 & $2,3 \mathrm{~b}$ \\
\hline
\end{tabular}

* Valores seguidos pela mesma letra na mesma coluna não diferem entre si pelo teste Tukey em $5 \%$ de probabilidade.

Médias entre 0 e 3= resistentes; Médias entre 3,1 e 5= suscetíveis.

** Os genótipos de números 3 a 15, 19, 21 e 22 são descendentes em $7^{\text {a }}$ geração do cruzamento entre a cv Santa Cruz 47 e a PI-357991.

diversos níveis de infecção radicular proposta por Taylor \& Sasser (1978), modificada como segue: $1=$ zero galhas ou ootecas; 2= uma a duas galhas ou ootecas; 3 = três a dez galhas ou ootecas; $4=$ onze a 30 galhas ou ootecas e $5=$ mais de 30 galhas e/ou ootecas por sistema radicular.

A análise estatística constou da aplicação do teste Tukey de comparação de médias sobre a média de três repetições das notas obtidas pela contagem do número de galhas ou ootecas presentes em cada sistema radicular dos indivíduos que representavam os diferentes genótipos.

\section{RESULTADOS E DISCUSSÃO}

Todos os genótipos em teste foram suscetíveis a $M$. javanica sem diferença ao nivel de $5 \%$ pelo teste de F. As médias das notas variaram de 3,3 a 5,0. Os genótipos CGO 8658 e CGO $8180 A_{8}$, com médias iguais a 3,3, foram os que mostraram maior tolerância ao patógeno, seguidos pelos genótipos CGO 8165A, CGO 8656 e CGO $8180 \mathrm{~A}_{7}$ com médias iguais a 3,6. Todos outros genótipos apresentaram notas médias superiores a 4,0.

Quanto à resistência a $M$. incognita, o CGO $8180 \mathrm{~A}_{7}$ diferiu significativamente dos demais com $5 \%$ de probabilidade, pelo teste deTukey (tabela 1), mostrando superioridade com relação às cultivares Piranema e Santa Cruz 47, que por sua vez, não diferiram dos demais. Os genótipos que obtiveram média de número de galhas ou ootecas com valor três ou inferior foram consideradas resistentes, caso a média da cultivar controle suscetível fosse maior do que 
quatro. Por outro lado, os genótipos que apresentaram média maior que três foram designados suscetíveis. Não foram caracterizados imunidades ou outros graus de resistência ao nematóide entre os genótipos de quiabeiro testados.

A resistência do acesso 'PI-357991' (A. esculentus) a Meloidogyne relatada por McLeod et al. (1983) não foi constatada nos seus descendentes, como pode ser observado nesse trabalho. É possível que este fato seja devido à variabilidade do patógeno ou segregações do material genético utilizado. Considerando também que a duração do ciclo de vida do nematóide-das-galhas das raízes é fortemente afetada pela temperatura (Taylor \& Sasser, 1983) e que, sob condições de altas temperaturas também ocorre queda de resistência (Van Der Plank, 1975), novas avaliações tornamse necessárias, uma vez que a temperatura em casa-de-vegetação oscilou entre 15 e $45^{\circ} \mathrm{C}$ durante o experimento.
Até o momento não se conhece fonte de resistência genética aos nematóides das galhas em germoplasma de quiabeiro. Entretanto, novas avaliações sob condições ambientais controladas deverão ser realizadas, para uma melhor discriminação dos genótipos mais promissores. Cabe ainda um redirecionamento do programa de melhoramento da cultura envolvendo novas recombinações genéticas.

\section{LITERATURA CITADA}

CHARRIER, A. genetic resources of Abelmoschus (okra). Rome: IBPGR, 1984. $61 \mathrm{p}$

COOK, R. Resistance in plants to cyst and rootknot nematodes. Agricultural Zoology Reviews, v. 4, p. 213-240, 1991.

HAMON, S.; CHARRIER, A.; KOECHLIN, J.; VAN SLOTEN, D.H. Potencial contributions to okra breeding through the study of their genetic resources. In: INTERNATIONAL OKRA GENETIC RESOURCES WORKSHOP, 1990, New Delhi. Anais...Roma: IBPGR, 1991. p. 77-88.
MILNE, D.L.; DU PLESSIS, D.P. Development of Meloidogyne javanica (Treub) Chitwood on tobacco under fluctuating soil temperature. South African Journal Agriculture Science, v. 7, p. 678680, 1964.

SASSER, J.N. Root-knot nematodes: a global menace to crop production. Plant Disease, v. 64, n. 1, p. 36-41, 1980

SIDHU, G.S.; WEBSTER, J.M. Genetics of plantnematode interactions. In : ZUCKERMAN, B.M.; ROHDE, R.A. (ed.) Plant Parasitic Nematodes. New York: Academic Press, 1981. v. 3, p. 61-87.

TAYLOR, A.L.; SASSER, J.N. Biology, identification and control of mot-knot nematodes (Meloidogyne sp.). North Carolina State University, N.C., 1978. $111 \mathrm{p}$

TAYLOR, A.L.; SASSER, J.N. Biología, identificación y control de los nematodos del nódulo de la raíz (Espécies de Meloidogyne). Universidad del Estado de Carolina del Norte, 1983. $111 \mathrm{p}$

TIHOHOD, D. Nematologia Agrícola. Jaboticabal: FCAV-UNESP, 1989. v. 1, 80 p.

TRUDGILL, D.L. Resistance and tolerance of plant parasitic nematodes in plants. Annual Review of Phytopathology, v. 29, p. 167-192. 1991.

VAN DER PLANK, J.E. Principles of Plant Infection. New York: Academic Press, 1975. $216 \mathrm{p}$ 